\title{
On the Buyability of Voting Bodies
}

\author{
John Morgan* \\ Haas School of Business and Department of Economics \\ University of California, Berkeley
}

Felix Várdy ${ }^{\dagger}$

Haas School of Business and International Monetary Fund, Washington, DC

November 2010

\begin{abstract}
We study vote buying by competing interest groups in a variety of electoral and contractual settings. While increasing the size of a voting body reduces its buyability in the absence of competition, we show that larger voting bodies may be more buyable than smaller voting bodies when interest groups compete. In contrast, imposing the secret ballot is an effective way to fight vote buying in the presence of competition, but much less so in its absence. Regardless of competition, the option to contract on both votes and outcomes is worthless, as it does not affect buyability compared to contracting only on votes. The option to contract on votes and vote shares, on

\footnotetext{
*E-mail: morgan@haas.berkeley.edu.

${ }^{\dagger}$ E-mail: fvardy@haas.berkeley.edu
} 
the other hand, is extremely valuable: it allows the first-mover to effectively nullify competition and obtain its preferred policy at almost the monopoly cost.

JEL \#s: D71, D72, D78.

Keywords: Vote buying, lobbying, corruption, elections. 


\section{Introduction}

In 1757, George Washington ran for a seat in the Virginia House of Burgesses, the colony's main legislative body. Concerned about the effects of drink on his soldiers, Washington ran an upstanding campaign on the platform of temperance. He was soundly defeated by 270 to 40 votes. The following year, Washington changed his platform and his tactics in another run for the same seat. To aid his chances, Washington offered voters an average of one and a half quarts of various alcoholic beverages in exchange for their votes. The difference in outcome was impressive. Against the same opponent, Washington won by 310 to 45 votes (Ford, 1896).

Since Washington's times, there have been considerable changes in the size of elections, the secrecy of the ballot, and the sophistication of vote buying contracts. For example, the total number of voters in Washington's elections was only about 350. The expansion of the voting franchise - perhaps most dramatically with the passing of the 19th Amendment in 1920 extending suffrage to women - has lead to considerably larger numbers in modern times.

At the same time, the growth in the size of the U.S. population has led to a considerable expansion of the size of federal legislative bodies. The House of Representatives now numbers 435 members, whereas it had only 65 at the time of the first Congress of 1789 . Similarly, with the admission of new states, the U.S. Senate has expanded from 26 members to its current total of 100 .

One may wonder whether an increase in the size of a voting body makes that body more or less susceptible to vote buying. ${ }^{1}$ If the cost per vote remained fixed, then, clearly, the direct effect of expanding the voting body makes vote buying more costly. This, however, ignores the strategic effect of competition in vote buying. In the face of competition, the 
scale of vote buying needed to secure the desired outcome depends on the response of a rival group. As Groseclose and Snyder (GS, 1996) have shown, the optimal way to blunt competition is to buy a supermajority of voters. However, the magnitude of the optimal supermajority varies with the size of the voting body and, indeed, it may be possible to economize on payments made for deterrent purposes as the size of the voting body grows. Thus, there is a countervailing strategic effect which is cost-reducing. An obvious question is whether this strategic effect can be sufficiently strong as to outweigh the direct effect.

A measure explicitly introduced to counteract vote buying was the imposition of the secret ballot. Motivated by Chartist principles and worried about the corruption endemic to its electoral process, in 1856, the Australian state of Victoria was the first to adopt the secret ballot in general elections. Britain and the U.S. soon followed. Yet, the effectiveness of the secret ballot as a deterrent to vote buying is debatable. Several studies suggest that the process of vote buying has simply shifted from simple schemes such as that employed by Washington to more intricate ones (see, e.g. Cox and Kousser, 1981 and Heckelman, 1998). A recent example of how vote buying has adapted to the secret ballot can be seen in the Taiwanese Presidential election of 2000. In that election, the ruling National Party subsidized betting parlors to offer extremely favorable odds on the event that the party's candidate, Lien Chan, was elected (August, 2000). This way, the ruling party managed to circumvent the secrecy of the ballot by offering a vote buying contract that was contingent on the outcome rather than on the vote itself. A central question is under what circumstances such schemes can succeed, as well as the cost-effectiveness of outcome-contingent vote buying.

Washington's scheme, as well as that of the National Party in Taiwan, are relatively simple in the sense that only a single contingency — vote or outcome - is contracted upon. There are other vote buying schemes that are more complex and involve multiple contingencies. For 
example, in the scandal of the 2002 Salt Lake City Olympic Winter Games, it was reported that certain members of the International Olympic Committee (IOC) were paid money in exchange for their votes, as well as a "bonus" conditional on the outcome of the vote -i.e., the success of the city's Olympic bid. ${ }^{2}$ Thus, the contracts depended both on votes and outcomes. Such sophisticated vote buying contracts, where payments are contingent on an individual's vote as well as some aggregate measure, can be found as far back as nineteenth century Great Britain. For instance, Seymour (1915, p.167) details how in elections held in Liverpool in the 1830s the price paid for votes rose and fell like a stock price, depending on the current vote shares of the candidates.

In this paper, we reexamine the model of Groseclose and Snyder (GS, 1996). First, we add a new element of realism to the model by endogenizing the order of moves. We then study how size, secrecy and sophistication affect the buyability of voting bodies. As we show, the effects of these three factors crucially depend on whether there is competition among interest groups seeking to influence voting outcomes.

Absent competition, increasing the size of the voting body provides effective protection against vote buying. In the presence of competition, this is no longer true: larger voting bodies may be more buyable than smaller voting bodies. In contrast, the introduction of the secret ballot has little effect on the buyability of voting bodies in the absence of competition. Specifically, it does not affect the cost of vote buying but may reduce the likelihood through equilibrium multiplicity. In the presence of competition, however, the beneficial effect of the secret ballot is unambiguous: the cost of vote buying is increased and the likelihood decreased relative to the GS case where individual votes are directly contractible.

In terms of complexity, or sophistication, we examine both discriminatory and nondiscriminatory vote buying. Here, discriminatory vote buying means that payments can be 
tailored to the individual preferences of voters. Non-discriminatory vote buying means that payments have to be the same for all voters who receive a bribe. Absent competition, the option of discriminatory vote buying always increases the buyability of voting bodies - it is always cheaper than non-discriminatory vote buying. In the presence of competition, this in no longer the case. Indeed, we identify conditions where the legislature is more buyable under non-discriminatory contracts than under discriminatory contracts.

Turning to more complex contracts, we show that the ability to contract on votes and outcomes has no effect whatsoever on the buyability of voting bodies, as compared to the case where only votes may be contracted upon. This is true independent of competition. However, the irrelevance of additional contractual contingencies does not generalize. When interest groups can contract on votes and vote shares, vote buying can become extremely cheap even in the presence of competition. This leaves the voting body uniquely at risk of "capture."

The remainder of the paper proceeds as follows. In section 2, we describe the model. Our model is exactly that of GS but for variations in the contractual environment and endogenous order of moves. In section 3 , we recapitulate - and extend to endogenous order of moves - the main result of the GS model, which characterizes the optimal discriminatory vote buying contract. Section 4 examines how policy responses to vote buying affect the buyability of voting bodies. Specifically, we study the effect of changes in size of the voting body and changes in the secrecy of the ballot. In section 5, we examine the effects of contractual complexity, or sophistication, on buyability. Section 6 places the results in the context of the broader literature. Finally, Section 7 concludes. Appendix A contains proofs of results presented in the main text, while Appendix B studies the robustness of results pertaining to non-discriminatory vote buying. 


\section{The Model}

We take as our starting point the GS model. ${ }^{3}$ We enrich this model in two ways. First, we endogenize the order of moves and, second, we vary the structure of contracts to permit various kinds of vote buying schemes.

There are an odd number, $n$, of voters choosing between two policies. The policies, which one could also think of as candidates or party platforms, are labeled $a$ and $b$. The policy receiving the majority of votes is adopted.

Two interest groups, labeled $A$ and $B$, are trying to affect the policy choice. Group $A$ prefers policy $a$ while group $B$ prefers policy $b$. In a setting where the voters are legislators, the interest groups can be thought of as lobbyists or political action committees. In a setting where voters are citizens voting in an election, the interest groups may be thought of as political parties. In this interpretation, the policy options refer to which party gets to form the government.

Excluding the cost of buying votes, group $A$ enjoys a payoff $W_{A}>0$ when policy $a$ is adopted and zero when $b$ is adopted. Group $B$, on the other hand, enjoys a payoff $W_{B}>0$ when policy $b$ is adopted and zero when $a$ is adopted. Thus, groups $A$ and $B$ have diametrically opposed policy preferences. To induce voters to vote for its preferred policy, each group can offer enforceable contracts, or "bribes." We will vary the contingencies on which these contracts can be based.

A natural question is how, exactly, these contracts are enforced when the contracts themselves are illegal. Clearly, parties entering into such contracts cannot rely on the courts for protection. We follow much of the preceding literature including GS and assume that (unmodelled) reputational effects are sufficient to make these contracts self-enforcing. ${ }^{4}$ The 
stringency of this assumption varies depending on the nature of the contractual form. For some contracts, such as the spot exchange of a voter's ballot for cash, self-enforcement would not appear to be a problem. For others, such as contracts contingent on aggregate outcomes, payments necessarily come later in time than the casting of the votes and hence the reputational "glue" needed to hold these agreements together is correspondingly greater.

The net payoff to a group is its payoff associated with the adopted policy less any vote buying costs. Throughout, we assume that $W_{A}$ is sufficiently large, such that offering contracts that successfully induce the adoption of policy $a$-if at all possible - is preferred by group $A$ over doing nothing.

As in GS, voters have expressive preferences. That is, they care about their actual votes, plus any transfers from the interest groups. Specifically, voter $i$ 's payoff, $i \in\{1,2, \ldots, n\}$, is

$$
U_{i}\left(c_{i}, t_{i}\right)=u_{i}\left(c_{i}\right)+t_{i}
$$

where $c_{i}$ indicates voter $i$ 's vote (choice), $a$ or $b$, while $t_{i}$ denotes any monetary transfers received from an interest group as a consequence of entering into a contract.

Of relevance is the change in a voter's payoff from switching his vote from $b$ to $a$. Hence, define

$$
v_{i}=u_{i}\left(c_{i}=a\right)-u_{i}\left(c_{i}=b\right)
$$

and suppose that all voters have strict preferences over $a$ and $b$; that is, $v_{i} \neq 0$ for all $i$. Next, almost without loss of generality, assume that the indices of voters are ordered such that $v_{i}$ is a strictly decreasing function of index $i$. And, for future reference, define $v^{-1}(x) \equiv \min \left\{i \mid v_{i} \leq x\right\}$. Furthermore, suppose that a supermajority of voters intrinsically prefers policy $b$; that is, $v_{M-1}<0 .{ }^{5}$ Hence, in the absence of interest group $A$, policy $b$ would be adopted, while policy $a$ is only adopted when interest group $A$ manages to buy the vote. 
In addition, we follow GS and assume that the preferences of the voters are commonly known to all parties. This assumption would appear to be appropriate in situations like small and public committees, where interest groups are likely to be aware of each voter's preferences. However, even in large elections, to the extent that observable characteristics such as race, gender, and metropolitan statistical area correlate with preferences, contracts specific to the preferences of voters (or at least specific to their observable characteristics) would still be possible.

For obvious reasons, the preferences of voters in the neighborhood of the median voter are of special interest. We assume that:

\section{Assumption 1. $v_{M}-v_{M+1} \leq \frac{W_{B}}{M}$.}

Assumption 1 merely rules out large jumps in the relative preference for policy $a$ versus policy $b$ between the median voter and the voter just to the right of the median. Most of the results contained in the paper do not rely on Assumption 1. Where a result does rely on this assumption, it will be explicitly invoked in the proof.

The extensive form of the game is as follows. In the run-up to the vote, which takes place at time $\tau=1$, interest groups can offer contracts to voters. Time is continuous and each interest group is free to make an offer at any point $\tau \in[0,1){ }^{6}$ An offer consists of a schedule of non-negative contingent transfers to all voters. This includes the possibility of offering some voter types a null contract (the promise of a zero transfer in all contingencies). Once an interest group makes an offer, its move is visible to its rival and it can make no further offers. If both groups try to make offers at the same time, a coin flip determines who goes first. If a group has made no offers by time $\tau=1$, it is assumed to have offered a null contract to all voters. 
Next, each voter opts for one of the two contracts he has been offered and votes. Finally, the policy outcome is determined through a simple-majority election and payoffs are realized. If an interest group can do no better than to propose null contracts to all voters, we assume that it opts for this strategy. Also, if a voter is indifferent between accepting the contract offered by $A$ and that offered by $B$, he is assumed to accept $A$ 's contract. Since the median voter prefers policy $b$, of interest is the case where group $A$ manages to defeat the intrinsic preferences of the voters and obtain its preferred policy $a$.

What happens when a given set of contracts leads to multiple equilibria, some of which produce victories for $A$ while others produce defeats? Owing to the exogenous ordering of moves and the restriction to vote-contingent contracts, this multiplicity does not arise in GS. In our more general setup, however, multiplicity may occur. For example, when contracts are contingent on outcomes, the contract itself creates interactive incentives. To address this issue, we shall take a conservative view about the cost of successful vote buying.

Definition 1 A vote buying contract is successful if and only if it guarantees adoption of policy a.

Formally, a vote buying contract is successful if and only if all subgame perfect equilibria following the contract lead to the adoption of policy a.

To rule out "nuisance" equilibria where one of the interest groups makes contract offers under the assumption that none of these will be accepted owing to a counteroffer by the other interest group, we use a trembling hand type refinement. ${ }^{7}$ Specifically, we assume that there is an infinitesimal possibility that no competing interest group is present. That is, with arbitrarily small probability, an interest group is a monopolist.

Next, we define "coalitions" and "outside options," concepts frequently used in the analy- 
sis.

Definition 2 A coalition for policy a consists of a set of voters who, given the contracts they have been offered, prefer to accept A's contract and vote for policy a.

A coalition for policy $b$ is defined analogously. Note that any voter who is not in $a$ 's coalition is in b's coalition. Also note that a winning coalition is a coalition with a cardinality of at least \#M.

Finally, consider any pair of contracts and the resulting coalitions of voters.

Definition 3 The outside option for a voter in the $b$ coalition is the payoff that the voter would receive if he unilaterally accepted A's contract.

The outside option for a voter in the $a$ coalition is defined analogously.

\section{Preliminaries}

In their seminal paper, Groseclose and Snyder consider the following case: group $A$ moves first, contracts are contingent only on votes, and offers made are specific to each voter. That is, they consider vote-contingent, discriminatory vote buying schemes with a fixed order of moves. While discriminatory schemes make sense in situations where there are relatively few voters with preferences known to the lobbying groups, even in large elections discriminatory

schemes are sometimes observed. For instance, in general elections in the Philippines, the vote buying strategies of major parties prescribe variable payments depending on the identity of the voter. As Quimbo (2002) writes:

The amounts [of the payments] may vary among supporters, the undecided, and those on the other side (...). Undecided voters sometimes get three times 
as much as supporters. Key supporters from the other side receive even more if they switch sides.

Here, we briefly recapitulate the main result of Groseclose and Snyder. Fix some coalition size $m$, such that $M \leq m \leq n$. Next, define $K(m)$ to be the minimum expected payoff including transfers earned by any voter $i=\{1,2, \ldots, m\}$ in a winning coalition for policy $a$. Moving first, group $A$ will offer bribes that induce a value $K(m)$ such that group $B$ will (just) not wish to "invade" $A$ 's coalition in order to implement policy $b$. See GS for details.

For $B$ to obtain its desired policy, it must re-bribe at least $m-M+1$ voters. Group $B$ needs to offer these voters transfers that exceed their expected net payoffs under the vote buying scheme proposed by $A$. By construction, this amount is at least $K(m)$. For $A$ to be successful, re-bribing must cost $B$ at least $W_{B}$. This implies that for fixed $m$,

$$
K(m)=\frac{W_{B}}{m-M+1}
$$

Conditional on $m, K(m)$ implicitly describes the least-cost successful vote buying scheme available to $A$. As GS show, for given $m$ the least-cost successful contract is:

For $v^{-1}(K(m)) \leq i \leq m$

$$
t_{i}=\left\{\begin{array}{ccc}
K(m)-v_{i} & \text { if } & c_{i}=a \\
0 & \text { if } & c_{i}=b
\end{array}\right.
$$

while to $i<v^{-1}(K(m))$ and $i>m$, the null contract is offered.

For future reference, we refer to a contract of this form as a $K(m)$ contract. The cost of such a contract is

$$
C_{A}(m)=\sum_{i=v^{-1}(K(m))}^{m} t_{i}
$$


Without proof, we offer the following proposition which follows directly from Groseclose and Snyder.

Proposition 1 Suppose that group A moves first. Let $m^{*} \in \arg \min C_{A}(m)$. Then a $K\left(m^{*}\right)$ contract is a least-cost successful contract under discriminatory vote buying.

Hence, when the option of offering discriminatory contracts is available, group $A$ optimally tailors the contract offered to each voter to account for that voter's intrinsic preferences. Voters with intrinsic preferences favoring policy a receive smaller transfers than those with intrinsic preferences favoring $b$. Indeed, the size of the transfer is increasing up to the voter with index $m^{*}$, who is offered the largest transfer for voting for $a$. Group $A$ optimally gives up on buying voters with intrinsic preferences toward $b$ that are greater than those of $m^{*}$.

The central insight of GS is that, generally, $m^{*}>M$. That is, it tends to be optimal for $A$ to buy a supermajority, because it decreases the total cost of deterring $B$.

Now suppose that we endogenize the order of moves of the interest groups. Our next proposition shows that the extensive form GS analyzed is in fact the unique subgame perfect equilibrium when the timing of bribes is also a strategic decision. To gain some intuition for why this is the case, let $C_{\text {Monopoly }}$ denote the cost to group $A$ of securing its preferred policy outcome as a monopolist, i.e., in the absence of group $B$. Notice that $A$ 's optimal strategy as a monopolist is very simple: It pays a transfer $-v_{i}$ to voters with types $v^{-1}(0) \leq i \leq M$ in exchange for voting for $a$. It may be readily verified that $C_{A}\left(m^{*}\right)>W_{B}+C_{\text {Monopoly }}$. This implies that it is never in B's interest to move first since, if it did, A could "neutralize" $B$ 's offers at a cost of at most $W_{B}$ and then get its most preferred policy at an additional cost of at most $C_{\text {Monopoly }}$. Hence, by moving first, $B$ only makes it cheaper for $A$ to buy the election. Finally, by assumption, group $A$ prefers moving first over not moving at all. 
Proposition 2 In any subgame perfect equilibrium of the vote buying game with endogenous moves, group A moves first.

Specifically, group A offers a least-cost successful contract at some time $\tau \in[0,1)$. If A offers a successful contract or has not yet offered a contract, $B$ does nothing. Otherwise, at some time $\tau^{\prime} \in(\tau, 1), B$ buys a minimum winning coalition at the lowest possible cost.

Why does $A$ go first when the timing of moves is endogenous? The key is that policy $b$ is favored by the majority of voters. Thus, $B$ can afford to wait knowing that, if there is inaction on both sides, its preferred policy will prevail. Indeed, if policy $a$ were favored by the majority, group $A$ would find it optimal to wait. Moreover, since $B$ benefits less than $A$ from having its preferred policy adopted, the result would be a "fair" election with neither side choosing to buy votes.

\section{Policy Responses to Vote Buying}

\subsection{The Size of the Voting Body}

Expanding the size of the voting body is commonly perceived to be a "cure" for vote buying. The intuition relies on the direct effect that such an expansion has on the costs of a single, monopsonistic lobbying group. While the size of the bribes remains the same, the lobbying group will have to bribe a larger number of voters. Clearly, this increases its costs. For marginal policies - policies where $W_{A}$ is not too large - the lobbying group will therefore refrain from influencing the vote with a large voting body, but will influence it with a small voting body. Of course, in the case where there is no competition this intuition is correct.

The presence of competition, however, introduces a strategic reason for bribing voters on 
the part of group $A$. Indeed, it is this strategic effect that is responsible for the Groseclose and Snyder result that bribing a supermajority of the voters is optimal.

What does the presence of the strategic effect do to the intuition that larger voting bodies are less buyable than smaller voting bodies? To study this formally, we need a way to scale the preferences of voters such that the relative strength of preferences does not vary with the size of the voting body. To do this, we introduce a continuous and strictly decreasing preference function $v(\cdot)$ on $[0,1]$ and impose a grid of size $n$ (odd) such that voter $i$ 's relative preference $v_{i}$ for $a$ is given by $v\left(\frac{i-1}{n-1}\right)$. The larger $n$, the finer the grid. Notice that the median voter, who has index $i=\frac{n+1}{2}$, always has the relative preference strength $v\left(\frac{1}{2}\right)$ independent of $n$. To ensure that the intrinsic preferences of the median voter favor policy $b$, we assume that $v\left(\frac{1}{2}\right)<0 .^{8}$

Our main result is to show that the strategic effect can be sufficiently strong that it overcomes the direct effect. As a consequence, larger voting bodies may be more buyable than smaller voting bodies. Indeed, as we also demonstrate, the cost of bribing a voting body may be non-monotonic in its size.

Proposition 3 It can be cheaper for group A to bribe a larger voting body than a smaller voting body.

The following simple example proves the proposition. Suppose that $W_{B}=1$ and that the preference function is

$$
v(x)=\left\{\begin{array}{ccc}
\frac{1}{3} & \text { if } & x<0.5 \\
-\frac{1}{1000} & \text { if } & 0.5 \leq x \leq 0.6 \\
-2 & \text { if } & x>0.6
\end{array}\right.
$$

That is, the voters are divided into three groups: 1) supporters of policy a (those with indices 
such that $\left.\frac{i-1}{n-1}<0.5\right), 2$ ) moderates (those with indices such that $\frac{i-1}{n-1}$ lies between 0.5 and $0.6)$ and, 3) strong supporters of policy $b$ (those with indices such that $\left.\frac{i-1}{n-1}>0.6\right) .^{9}$

In that case, it is a simple matter to show that the least-cost successful contract entails group $A$ optimally bribing all its supporters as well as up to three moderates. Since strong supporters of policy $b$ dislike policy $a$ intensely $\left(v_{i}=-2\right)$, it is never cost-effective for group $A$ to bribe these voters. When there are three or fewer moderates, group $A$ economizes on its overall payments by bribing all of them. Once there are three moderates in the coalition, however, group $A$ no longer pays its supporters anything and, therefore, further expansion of the supermajority generates no savings.

Figure 1 displays $A$ 's total costs as the size of the voting body varies. It is interesting to note the points in the figure where the costs jump. These jumps occur when the number of moderates increases by exactly one voter - which happens when the size of the voting body increases by 10 voters - until there are three moderates, which occurs when the voting body consists of 21 voters.

$<<$ Place Fig. 1 about here. Caption: "Figure 1: Cost of Discriminatory Vote Buying as a Function of $n ">>$

At these jump points, the strategic effect is operative. Consider the first jump point, which occurs when the voting body grows from 9 to 11 members. In that case, group $A$ is able to cut by half the amount of the surplus, $K\left(m^{*}\right)$, it has to guarantee each of the voters in its coalition in order to deter $B$. This economization occurs for the standard supermajority reasons. Since this payment was previously being made to all intrinsic supporters of policy $a$ as well as all the moderates, its reduction more than offsets the increasing costs associated with the direct effect of having to bribe two more voters. 
The next jump point, which occurs when the voting body grows from 19 to 21 members, illustrates the same effect. Here, the amount of the surplus required to deter $B$ falls to $\frac{1}{3}$. Hence, group $A$ no longer has to pay its intrinsic supporters at all while it continues to save on payments to moderates. Once the number of moderates is three or more, there is no additional scope for economies due to the strategic effect. Hence, the direct effect dominates. But in the example, the direct effect is zero owing to the zero payments to supporters.

\subsection{The Secret Ballot}

A common strategy to deter vote buying is the imposition of the secret ballot. Clearly, the idea is that making individual votes unobservable prevents lobbying groups from contracting (formally or informally) on individual votes. An early expression of this idea is found in the Chartist Petition of 1838, which states:

The suffrage, to be exempt from the corruption of the wealthy and the violence of the powerful, must be secret. (Webster, 1920, p. 145).

Indeed, the infusion of Chartist ideas is widely credited with the decision of various Australian territories to implement the secret ballot in the 1850s, with the English and several American states adopting the practice later in the 19th century (Newman, 2003).

In response to the secret ballot, interest groups have devised a number of clever strategies to continue to buy individual votes. One such strategy is known as the Tasmanian Dodge, which arose in response to the early Australian reform efforts. In this scheme, an interest group steals or forges a single empty ballot before the vote. It then fills out this ballot and provides it to a voter. The voter casts the filled-out ballot while receiving a new, blank ballot from the polling station. The blank is then returned to the interest group in exchange for 
payment and the process is repeated. ${ }^{10}$

Caro (1982) describes less subtle strategies used to circumvent the secret ballot in Texas in the 1930s:

Election supervisors would, in violation of law, stand alongside each voter in the voting booths to make certain that each vote was cast as paid for. (p.719) Even if the voter was allowed to cast his ballot in secrecy, he had little chance of escaping unnoticed if he disobeyed instruction; each ballot was given a number that corresponded to the number on a tear-off sheet attached to the ballot, and a voter had to sign his name on the sheet before it was torn from the ballot and the ballot cast. (p. 721)

While safeguards have been put in place to counteract practices like these, it is interesting to note that recent initiatives designed to spur voter turnout may actually undermine the secrecy of the ballot. For instance, the state of California recently implemented a policy allowing voters to become "permanent absentee voters," which saves them the trip to the polling station. As with standard absentee balloting, voters -are mailed paper ballots in advance of the election. They fill them out at home and send them back. It would be a simple matter for an interest group to buy blank - but signed - paper ballots from permanent absentee voters. The interest group could then fill out the ballots as desired and mail them in.

Still another way to circumvent the secret ballot is "negative vote buying" - the practice of paying opposition supporters in exchange for their not voting in an election. Cox and Kousser (1981) offer a thoughtful analysis of the effects of this practice on voter turnout in New York state by reviewing newspaper articles describing various instances of (positive and) 
negative vote buying. (See also Heckelman, 1998.) Formally analyzing the case of negative vote buying requires amending the model to allow for a third choice, namely, abstention, and specifying payoffs for this choice. Since the spirit of the present paper is to further analyze the model of Groseclose and Snyder, which has no abstention, we omit consideration of this case. $^{11}$

In certain instances, the schemes discussed above to circumvent the secrecy of the ballot may be either infeasible (owing to adequate safeguards) or impractical (perhaps owing to scale, as in general elections). In that case, it may still be possible to circumvent the secret ballot by relying on contracts based on outcomes rather than individual votes. Since policy outcomes remain observable, such schemes are feasible in virtually all circumstances, and they scale in a practical fashion. As mentioned in the Introduction, a real world example can be found in the 2000 Taiwanese presidential election. Here, the ruling party set up subsidized betting parlors that offered extremely favorable odds on a bet that paid in the event that Lien Chan, the ruling party's candidate won the race (August, 2000). Thus, a voter accepting such a bet was entering into a contract where the ruling party's payment to him was entirely dependent on the outcome of the election.

When contracting is possible only over outcomes, is it still the case that lobbying groups can successfully bribe voters? How costly are such schemes to implement relative to contracting on votes directly? To study these questions, we now analyze the case where the two interest groups are limited to offering voter-specific (that is, discriminatory) contracts contingent only on the policy outcome.

The next proposition shows that introduction of the secret ballot is indeed beneficial: group $A$ cannot offer bribes in such a way as to guarantee its most preferred outcome. 
Proposition 4 Successful vote buying contracts do not exist when only outcomes are contractible.

One may wonder what goes wrong for group $A$ when interest groups can only contract over outcomes. The problem stems from the fact that incentives are only created in case a voter believes that he is pivotal. But because there is supermajority intrinsic support for policy $b$, even if group $B$ does nothing, there always exists an equilibrium in which voters ignore the contract offered by $A$ and vote according to their intrinsic preferences. Clearly, in such a situation, no voter perceives himself as pivotal and, hence, the incentive effects of A's contract are nullified. ${ }^{12}$ Note that this argument does not rely on any particular order of moves.

While the previous result shows that $A$ cannot guarantee its preferred policy outcome under supermajority opposition, does there exist an equilibrium in which $A$ obtains its preferred policy? The next proposition shows that, even under the secret ballot, there exists an equilibrium in which $A$ successfully buys the election. Interestingly, the contract offered by $A$ to achieve this outcome at the lowest possible cost closely resembles the contracts derived by Groseclose and Snyder. Again, the equilibrium construction is independent of the order of moves.

Proposition 5 When only outcomes are contractible, a $K(M)$ contract is a least-cost contract such that there exists an equilibrium in which policy a is adopted.

Recall that when votes were contractible, group $A$ moved first in all subgame perfect equilibria. When only outcomes are contractible, this is no longer the case. In particular, self-fulfilling beliefs allow for a variety of equilibrium outcomes in terms of order of moves. For instance, suppose that voters hold beliefs such that if $B$ moves before $\tau=\frac{1}{2}$, then voting 
is according to intrinsic preferences and policy $b$ is adopted, whereas if $B$ moves after $\tau=\frac{1}{2}$, then $A$ 's most preferred equilibrium is played. Clearly, $B$ will find it optimal to move before $\tau=\frac{1}{2}$ in such a setting, while $A$ will (weakly) prefer to wait until after $\tau=\frac{1}{2}$ and simply hope that $B$ will have failed to move on time.

Combining the results of Proposition 1 and 5, a cost ranking across simple contracts arises.

Corollary 1 It is always cheaper for A to contract on votes than to contract on outcomes.

The bluntness of the outcome-based contractual instrument limits $A$ to trying to buy a bare majority rather than a supermajority of voters. The reason is that the incentive effects of the contracts, which depend on a voter being pivotal, are undermined if $A$ tries to buy a supermajority. Buying a bare majority rescues the incentive effects but is generally very expensive if it is to deter group $B$ from re-bribing. The upshot is that the incentives for legislative capture are significantly reduced.

Propositions 4 and 5 suggest that, in the presence of competition, the introduction of the secret ballot offers quite a powerful remedy against vote buying. It is interesting to contrast this result with the effect of the secret ballot in the absence of competition. Let group $A$ offer all voters up to the median whose intrinsic preferences favor policy $b$ an outcome contingent contract that pays $-v_{i}$ if policy $a$ is adopted and pays nothing if policy $b$ is adopted. In that case, group $A$ still cannot guarantee the adoption of its preferred policy. ${ }^{13}$ However, if it is adopted, it costs group $A$ exactly the same as when $A$ could contract on votes directly. Therefore, if $A$ succeeds, its cost under the secret ballot is no more than under the open ballot. Moreover, if $A$ does not succeed, it will not have to pay anything. Hence, in the absence of competition, the introduction of the secret ballot will not deter group $A$ from 
trying to buy the vote.

We conclude that the secret ballot is more effective as a means to prevent vote buying in the presence of competition than in its absence. Also, note that the secret ballot is not without costs; most notably, the loss of accountability in settings such as legislatures. Arguably, it is important that constituents be able to hold an elected legislator accountable on the basis of his voting record.

\section{Complexity}

Some real-world vote buying contracts are contingent on a combination of an individual's vote and the policy outcome. As mentioned in the Introduction, an example of such a contract came to light in the course of the bribery investigation into Salt Lake City's bid for the 2002 Olympic Winter Games. According to press reports, certain members of the IOC received payments ranging from $\$ 500,000$ to $\$ 1$ million in exchange for their votes. In addition, a "bonus" of $\$ 3-5$ million was to be paid if the city won the Olympic bid. ${ }^{14}$ How does vote buying change when one considers more complex contracts, with multiple contractual contingencies? Are policy making bodies such as the IOC more or less susceptible to outside influence under these circumstances?

In other instances, real-world vote buying contracts are less complex than the benchmark case studied in GS. For instance, in some circumstances, the assumption that one can tailor the payment in the contract to the preferences of an individual voter may be unrealistic. How does vote buying change when only non-discriminatory contracts can be offered? Does the inability to "target" payments to voters make the voting body more immune to influence?

To examine these questions, we consider three variations in the complexity of contracts. 
The first two allow for multiple contractual contingencies: contracts where payments are contingent on individual votes and policy outcomes, and contracts where payments are contingent on individual votes and vote shares. The third variation is, in some sense, the simplest possible vote buying contract - pure vote buying with the additional restriction that the contingent payment is non-discriminatory.

\subsection{Contracting on Votes and Outcomes}

The possibility of conditioning bribes on both votes and outcomes would seem to offer strategic opportunities for $A$ to reduce its costs of obtaining its preferred policy. As the next proposition shows, however, this is not the case. The least-cost successful contract costs $A$ exactly the same as when it contracted solely on votes and ignored the outcome altogether. As with the case when only votes are contractible, we first prove the result under the assumption that group $A$ moves first. Then, in Proposition 7, we use the thus-derived least-cost successful contract to show that this is without loss of generality: in all subgame perfect equilibria group $A$ moves first.

Proposition 6 When A moves first and contracts can be contingent on votes and outcomes, then a $K\left(m^{*}\right)$ contract is a least-cost successful contract for $A$.

Why does the possibility of conditioning on outcomes not help in any way? Notice that, while $A$ could offer the $K\left(m^{*}\right)$ contract under the joint contingency of a vote for $a$ and policy $a$ being adopted, this would save no money in equilibrium. In addition, such a contract is vulnerable to exploitation by $B$. In particular, $B$ can recruit a supermajority at arbitrarily small cost. As long as voters believe that B's supermajority coalition will hold together, there is no upside to switching one's vote to $A$. Hence, even though $A$ could contract not to 
pay in the event of a loss, it is, in fact, optimal to offer to pay. Indeed, this is essential in precluding $B$ from attempting to recruit a supermajority.

Note that the contract in the Olympic vote buying scandal does not correspond to the least-cost successful contract derived in Proposition 6. After all, the bonus payment is outcome-contingent. One obvious explanation for the discrepancy is that lobbying groups may be budget constrained. Indeed, Salt Lake City found itself with considerably more financial resources after its bid was successful than before, and this may have necessitated the bonus scheme. It is well-known that, even in simpler contractual settings, the introduction of budget constraints creates substantial complications in the analysis (see, for instance, Dekel, Jackson and Wolinsky, 2005). While we think that budget constraints have an important role to play in the analysis, we leave this for future research. Another possible explanation for the discrepancy is that outcome-contingent bonuses give IOC members an incentive to lobby colleagues. In terms of the model, this would mean that $v_{i}$ is not a constant and can be influenced.

To conclude, we show that the analysis remains unchanged when we endogenize the order of moves.

Proposition 7 When contracts can be contingent on both votes and outcomes, then, in all subgame perfect equilibria, A moves first.

\subsection{Contracting on Votes and vote shares}

As we saw above, the ability to contract on votes and outcomes provides no benefit for group $A$ relative to conditioning only on votes. However, if votes are publicly observable, then the lobbying group could also choose to condition on votes and vote shares, instead of on votes 
and outcomes. In an interesting paper, Dal Bo (2007) shows that, when voters care only about outcomes, this contractual contingency provides a powerful lever for a lobbying group in the absence of competition. Here, we examine this class of contracts in the presence of competition when voters care about their actual votes.

Let $\# a$ denote the number of votes cast for policy $a$. The number of votes for $b$, \#b, is then $n-\# a$. As before, we first assume that $A$ moves first. For that case, we show that

Proposition 8 When $A$ moves first and contracts can be contingent on votes and vote shares, then the following is a least-cost successful contract for A:

$$
\begin{aligned}
& \text { For } v^{-1}(K(M+1)) \leq i \leq M+1 \\
& t_{i}=\left\{\begin{array}{cccc}
\max \left(-v_{i}, 0\right) & \text { if } & c_{i}=a & \text { and } \# a \geq M+1 \\
K(M+1)-v_{i} & \text { if } & c_{i}=a & \text { and } \# a<M+1 \\
0 & \text { if } & c_{i}=b
\end{array}\right.
\end{aligned}
$$

To $i<v^{-1}(K(M+1))$ and $i>M+1$, the null contract is offered.

How does the above contract work? Notice that, to be successful, group $A$ must deter $B$ from recruiting a bare majority as well as a supermajority. To deter $B$ from recruiting a bare majority, group $A$ must promise to pay recruited voters sufficiently lavishly in the event that their votes turn out to be pivotal. To deter $B$ from recruiting a supermajority, group $A$ must promise to pay recruited voters sufficiently lavishly in the event that their votes turn out to be part of a losing effort on behalf of $A$, even when they are not pivotal. The contract described in Proposition 8 achieves this by promising each voter a surplus of $K(M+1)$ under either of these events and, as in GS, this amount is sufficient to deter $B$.

Note, however, that if $A$ manages to recruit a supermajority of voters, then, in equilibrium, voters in group $A$ 's coalition are neither part of a bare majority nor part of a losing 
effort. In other words, the circumstances where group $A$ is required to reward voters lavishly are off the equilibrium path. On the equilibrium path, group $A$ recruits a supermajority and compensates voters only for the disutility of voting against their preferred option. The contract described in Proposition 8 achieves this by promising voters zero net surplus in the event they are part of a winning supermajority coalition on behalf of $A$.

The idea that an interest group might want to pay voters for a losing effort is not merely a theoretician's flight of fancy. In his "Billionaire's Buyout Plan," Buffett (2000) half-jokingly suggested a similar mechanism. To pass campaign finance reform, he proposed that "some eccentric billionaire (not me, not me!) make the following offer: If the bill were defeated, this person - the E.B.- would donate $\$ 1$ billion in an allowable manner (soft money makes all possible) to the political party that had delivered the most votes to getting it passed." If the bill passed, however, the E.B. would donate nothing.

The mechanism that allows group $A$ to economize on payments on the equilibrium path works for any size supermajority. A natural question is why the least-cost contract involves recruiting a minimal supermajority rather than a larger one. The reason is that the usual strategic motive for recruiting a supermajority - to lower the costs of deterring group $B$ - is absent here. The costs of deterrence are incurred only off the equilibrium path. So savings in this regard are irrelevant. Instead, all that is left is the direct effect of having to compensate voters for voting against their intrinsic preferences. Obviously, this direct cost is minimized by choosing the smallest possible supermajority.

Note, however, that the assumption that $A$ moves first is not without loss of generality when groups can contract on votes and vote shares. If $B$ moves first, it can also write a contract that essentially nullifies competition. To characterize this contract, we need the analogue to $K(m)$ for the case where $B$ moves first. 
Fix a coalition of size $n-m$, such that $m<M$. Assuming that $B$ moves first, define $L(n-m)$ to be the minimum expected payoff earned in the standard vote buying game à la GS by any voter $i=\{m+1, m+2, \ldots, n\}$ in a winning coalition for policy $b$, where payoffs include transfers. Moving first in the GS game, group $B$ will offer bribes that induce a value $L(n-m)$ such that group $A$ will just not wish to "invade" $B$ 's coalition in order to implement policy $a$. For $A$ to obtain its desired policy, it must re-bribe at least $M-m$ voters. Group $A$ needs to offer these voters transfers that exceed their expected net payoffs under the vote buying scheme proposed by $B$. By construction, this amount is at least $L(n-m)$. For $B$ to be successful, re-bribing must cost $A$ at least $W_{A}$. This implies that for fixed coalition size $n-m$,

$$
L(n-m)=\frac{W_{A}}{M-m}
$$

Proposition 9 below offers a least-cost successful contract where $B$ obtains its preferred policy at zero cost. (The proof of this proposition is omitted, as it is exactly analogous to that of Proposition 8.)

Proposition 9 When $B$ moves first and contracts can be contingent on votes and vote shares, then the following is a least-cost successful contract for B:

For $M-1 \leq i \leq v^{-1}(-L(M+1))$

$$
t_{i}=\left\{\begin{array}{cccc}
0 & \text { if } & c_{i}=b & \text { and } \# b \geq M+1 \\
L(M+1)+v_{i} & \text { if } & c_{i}=b & \text { and } \# b<M+1 \\
0 & \text { if } & c_{i}=a
\end{array}\right.
$$

To $i<M-1$ and $i>v^{-1}(-L(M+1))$, the null contract is offered.

Propositions 8 and 9 imply that by contracting on votes and vote shares, the first mover is able to (almost) completely deflect the effects of competition. Formally, 
Corollary 2 The first mover's least-cost successful contract when a rival is present costs him the same as when the rival is absent and $M+1$-instead of $M$-votes are required for passage of a policy.

By conditioning on votes and vote shares, the first mover can offer deterring incentives without actually having to pay for them in equilibrium. Corollary 2 thus highlights the susceptibility of voting bodies to vote buying in rich contractual environments. The policy prescription here is clear. Contingent contracts along the line specified above must be made extremely costly, perhaps by penalties such as forfeiture of office or heavy fines.

To conclude, both $A$ and $B$ will try to move at the first possible instance, i.e. at $\tau=0$. The model specifies that in that case, a coin toss determines which of the two actually gets to make the first offer and, thus, achieves his preferred policy at (almost) the monopoly cost.

\section{Buying out the Competition}

Following Groseclose and Snyder, we have so far assumed that it was impossible for group $A$ to directly contract with $B$ and thereby remove the threat of competition prior to contracting with voters. Indeed, it is straightforward to show that, for the class of simple contracts (and, by extension, contracts contingent on votes and outcomes), contracting directly with $B$ is cheaper for group $A$ than contracting solely with voters.

There are some real-world situations in which buying out the competition is indeed feasible. For example, in the Lebanese parliamentary elections of 1960, the following incident occurred:

[A] candidate (...) was offered $\$ 7,000$ to quit the race for the less than $\$ 6,000$ a-year Deputy's [member of Parliament's] job. With pay so small, why was the bribe so high? Explained one candid hopeful: "Any Deputy is sure to be invited 
to become a bank director - at $\$ 4,000$ a year. Also, there's always the wayward young man whose parents will pay $\$ 1,500$ to spring him from jail. And then a Deputy gets immunity from police searches of his car. Any time he drives out to the country, he can load up with $\$ 1,000$ worth of hashish." (Time, Monday, Jun. $27,1960)$

With this example in mind, let us compare the cost of contracting on votes and vote shares with the cost of buying out the competition. Clearly, to buy out group $B$, group $A$ can make a take-it-or-leave-it offer of $W_{B}+\varepsilon$, for arbitrarily small $\varepsilon$. Group $B$ will accept and, subsequently, $A$ can contract with voters under monopsony conditions. The total cost to $A$ of this scheme is

$$
C_{A}=\sum_{i=0}^{M} \min \left(-v_{i}, 0\right)+W_{B}+\varepsilon
$$

If $A$ manages to move first and can contract on votes and vote shares, it incurs a cost of

$$
C_{A}^{\prime}=\sum_{i=0}^{M} \min \left(-v_{i}, 0\right)-v_{M+1}
$$

Thus, under the restriction that interest group $B$ cares more about policy $b$ than voter $M+1$, it follows that,

Remark 1 When A gets to move first, it is cheaper to only contract with voters than to first buy out the competing interest group $B$.

\subsection{Non-Discriminatory Vote Buying}

Often times, it may be difficult for lobbying groups to arrange payments in a discriminatory fashion. For instance, determining the exact preferences of individual voters may difficult. Another possibility is that, even if these preference are known, devising variable payment 
schemes may pose a considerable logistical challenge. Indeed, in many real-world instances of vote buying, interest groups rely on simple, non-discriminatory schemes. For instance, Caro (1982) recounts a vote buying strategy undertaken by Lyndon Johnson who, at the time, was working for Maury Maverick in his run for Congress in 1934:

Johnson was sitting at a table in the center of the room-and on the table there were stacks of five-dollar bills. "That big table was just covered with money - more money than I had ever seen," Jones says. (...) Mexican American men would come into the room one at a time. Each would tell Johnson a number - some, unable to speak English, would indicate the number by holding up their fingers - and Johnson would count out that number of five-dollar bills, and hand them to him. "It was five dollars a vote," Jones realized. "Lyndon was checking each name against a list someone had furnished him with. These Latin people would come in, and show how many eligible votes they had in the family, and Lyndon would pay them five dollars a vote."

This vote buying strategy was not unique to the Maverick campaign. Indeed, the practice of distributing fixed cash payments in exchange for votes, was (and perhaps still is) widespread. For instance, on p. 647, Caro writes:

Texas was not the only state in which money was piled on tables to purchase votes, just as Mexican-Americans were not the only immigrants whose votes were purchased. (...) big oak desks of city officials were traditionally cleared on Election Day and covered with piles of cash. In the big cities of the Northeast, votes might cost more than five dollars each. 
How do situations where vote buying is non-discriminatory compare to the case analyzed by Groseclose and Snyder? In particular, are voting processes more immune to outside influence under non-discriminatory vote buying than in circumstances where discriminatory (vote-contingent) contracts are possible? As usual, we first consider the case in which group $A$ moves first. Later, we show that this is without loss of generality; when the timing of moves is endogenous, group $A$ moves first in any subgame perfect equilibrium.

Let $t_{A}$ be the (uniform) transfer offered by group $A$. For now, assume that the interest groups cannot ration their offers. That is, $t_{A}$ is offered to all voters who want it. Let $m\left(t_{A}\right)$ be the highest index $i$ such that $v_{i}+t_{A} \geq 0$. Clearly, if $B$ offers the null contract, then all voters $i=1, \ldots, m\left(t_{A}\right)$ will accept the $t_{A}$ contract offered by $A$ and vote accordingly. We now characterize the minimal transfer that $A$ can offer and still be successful.

Proposition 10 Suppose that vote buying is non-discriminatory and group A moves first. Under the least-cost successful contract, group A offers payments in the amount $t_{A}=\frac{W_{B}}{M}-$ $v_{M}$. Group $B$ offers the null contract. All voters with indices $i \leq m\left(t_{A}\right)$ are in $A$ 's coalition.

It is interesting to contrast the structure of the least-cost successful contract in the non-discriminatory case with the discriminatory case of Groseclose and Snyder. In both cases, transfers can be viewed as consisting of two parts: 1) a compensatory payment to offset intrinsic preferences favoring $b$ and, 2) a surplus payment to deter $B$ from offering any contract other than the null contract. In the case of discriminatory contracts, the compensatory payments, $-v_{i}$, vary with the strength of preferences of the individual voter, while for non-discriminatory contracts they cannot. In the latter case, the compensatory payment, $-v_{M}$, is determined by the intrinsic preferences of the median voter. Clearly, all voters with indices to the left of the median will be sufficiently compensated as well. Under 
both types of contracts, the surplus payment does not vary with the identity of a bribed voter.

In the case of discriminatory contracts, the surplus payment is $\frac{W_{B}}{m^{*}-M+1}$, which reflects the fact that group $B$ can offer contracts to $m^{*}-M+1$ selected voters to obtain a bare majority of support for policy $b$. In contrast, the surplus payment offered under non-discriminatory contracts is lower and equal to $\frac{W_{B}}{M}$. The reason is that group $A$ is able to economize on the surplus transfer by recognizing that $B$ cannot target selected voters to "pick off" $A$ 's coalition.

GS show that it is generally optimal for group $A$ to buy a supermajority of voters when vote buying is discriminatory. The next proposition shows that the same result holds under non-discriminatory vote buying.

Proposition 11 Suppose that vote buying is non-discriminatory and that Assumption 1 holds. Then, under a least-cost successful contract, A always buys a supermajority of voters.

The intuition for this result is quite simple and almost identical to the proof. If $A$ were to buy a simple majority under non-discriminatory vote buying, then it must be that voter $M$ accepts the contract, while voter $M+1$ chooses not to accept the same contract. By Assumption 1, the intrinsic preferences of $M$ and $M+1$ are not too dissimilar. Therefore, the net surplus of voter $M$ under $A$ 's contract must be quite close to zero. (Else, $M+1$ would also accept the contract.) But this implies that $B$ can successfully invade $A$ 's simple majority by offering a very small bribe equal to $M$ 's net surplus under $A$ 's contract, plus $\varepsilon$. Hence, under non-discriminatory vote buying, a contract in which $A$ buys only a simple majority cannot be successful.

One may worry that this result relies heavily on the modeling assumption that neither of the lobbying groups can ration their transfers. After all, it seems that $A$ would be happy to 
stop making payments once a bare majority coalition was obtained. However, this ignores the strategic effect of $B$ 's response in the presence of rationing. In Appendix B, we show that adding rationing to the model does not change the basic conclusion that buying a supermajority is optimal.

Finally we endogenous the order moves.

Proposition 12 When contracts are non-discriminatory then, in all subgame perfect equilibria, A moves first.

\section{Which is less costly: Discriminatory or Non-Discriminatory Vote Buying?}

Absent competition, discriminatory vote buying is cheaper than non-discriminatory vote buying. The reason is that compensatory payments are smaller under discriminatory vote buying while surplus payments are the same, namely, zero. With competition, however, it is no longer so clear which scheme is cheaper for $A$, because surplus payments are smaller under non-discriminatory vote buying. Hence, the ability to discriminate has both advantages and disadvantages for $A$. The advantage is that $A$ does not have to pay its strongest supporters at all and can pay its weaker supporters less than it pays those who oppose policy $a$. The disadvantage is that $B$ can also discriminate and therefore specifically target the "weakest links" in $A$ 's coalition. When discrimination is not possible, such a targeted counter attack is not feasible. Which effect ultimately dominates depends on the shape of the preference function $v_{i}$.

Circumstances where (non-)discriminatory contracts are cheaper may be readily identified through a simple graphical analysis. In the figures below, we fix the preferences of the median voter and change the shape of the preference function around this point. 
A case where discriminatory vote buying is more cost-effective is shown in Figure 2. Illustrated in the figure are the preferences of voters, $v_{i}$, as well as the transfers made by $A$ under discriminatory and non-discriminatory vote buying. Since $m^{*}$ is close to $n$, the transfers paid by $A$ to voters located to the right of the median are almost the same under the two schemes. Where the schemes differ is in the transfers made to voters located to the left of the median, most of whom intrinsically prefer policy $a$. In the discriminatory case, few of these voters receive transfers, whereas in the non-discriminatory case, all of them receive transfers. Thus, the discriminatory scheme is clearly cheaper.

$<<$ Place Fig. 2 about here. Caption: "Figure 2: Cheap Discriminatory Vote Buying" $>>$

The opposite case, where discriminatory vote buying is less cost-effective, is illustrated in Figure 3. Since $m^{*}$ is close to $M$, the transfers to deter $B$ are considerably higher in the discriminatory case than in the non-discriminatory case. Moreover, owing to the steepness of the preference function to the right of the median, those receiving transfers from $A$ under the two schemes are almost the same. Where the schemes differ is in the size of transfers to voters to the left of the median. The lack of intrinsic support for policy $a$ means that under both schemes, all voters with indices smaller than $M$ receive payments, but these payments are considerably larger in the discriminatory scheme than in the non-discriminatory scheme.

$<<$ Place Fig. 3 about here. Caption: "Figure 3: Cheap Non-Discriminatory Vote

$$
\text { Buying" >> }
$$




\section{Related Literature}

Having presented the results of our paper, we now place our analysis in the context of the existing theoretical literature on vote buying. Obviously, our paper builds on the seminal

work of Groseclose and Snyder and extends their model both in terms of the contracting environment and the order of moves. ${ }^{15}$

We are aware of two other papers that have considered complex vote buying contracts. Dal Bo (2007) studies contracts involving votes and vote shares; however competition is absent in his model. Dekel, Jackson, and Wolinsky (2005) study contracts based on votes and outcomes. However, their model differs from ours in several respects - voters are nonstrategic, interest groups are budget constrained, and the process of vote buying is modeled as an alternating offer scheme.

Our paper is also somewhat related to the literature on how the structure of electoral systems affects corruption in government. Notable in this literature is Meyerson (1993) who examines how electoral systems differ in their ability to sort between corrupt and noncorrupt candidates running for office. ${ }^{16}$ In contrast, our concerns are not about sorting among candidates with varying corruption levels. Rather, we are interested in how electoral systems differ in their susceptibility to vote buying.

There is a large literature on the buying and selling of influence that differs significantly in both its concerns and modeling approach from our work and the papers above. Specifically, voting plays little role, as the policy is typically determined by a single player. Some of the earliest work in this area (see Tullock, 1972, 1980) models the policy maker as non-strategic and supposes that competition among interest groups takes the form of an imperfectly discriminating all-pay auction, or contest. One of the primary concerns of this literature is 
how variation in the structure of the auction affects rent-seeking expenditures by lobbying groups. The interested reader should consult Nitzan (1994) for an excellent survey. Another important approach to modelling competition for influence is the use of menu auctions (Bernheim and Whinston, 1986). Unlike the rent-seeking literature, here, the policy maker is modeled as a strategic player. The seminal work along these lines is Grossman and Helpman (1994) who apply this analysis to trade policy. Other notable work includes Grossman and Helpman $(1996,1999)$.

\section{Conclusions}

We have studied the buyability of voting bodies such as legislatures, committees, and electorates, under a variety of circumstances. First, we have investigated how the cost of successful vote buying depends on the size of the voting body. We found that increasing the size of the body increases the cost of vote buying when there only is a single interest group seeking to influence the outcome. In contrast, when there are competing interest groups, larger voting bodies may actually be cheaper to buy than smaller voting bodies.

Competition also plays an important role in the effectiveness of the secret ballot as an antivote buying measure. We have modelled the secret ballot as forcing vote buying contracts to be outcome-contingent rather than vote-contingent. In the presence of competition, this policy does have the intended effect: successful vote buying is more expensive under the secret than under the open ballot. In contrast, the secret ballot is significantly less effective as an anti-corruption measure when there is only one interest group.

Finally, we have studied how contractual complexity affects the buyability of voting bodies. We compared buyability under discriminatory and non-discriminatory vote buying. 
While discriminatory vote buying is clearly cheaper in the absence of competition, nondiscriminatory vote buying may actually be less costly when interest groups compete. We also studied the buyability of voting bodies when vote buying contracts can depend on multiple contingencies. Specifically, we looked at contracts contingent on votes and outcomes, and contracts contingent on votes and vote shares. While the option to add outcome-based contingencies to vote-based contracts turned out to be worthless, the option to make contracts depend on vote shares as well as on individual votes turned out to be extremely valuable. Availability of such contracts allows the first-mover to effectively nullify competition and obtain its preferred policy at approximately the same cost as when it is a monopoly.

Taken together, what are the implications for policy makers? First, it is important to note that the presence of competition is by no means a guarantee that policy outcomes reflect the underlying preferences of voters. Perhaps more surprisingly, the presence of competition does not even necessarily raise the cost of buying the vote. Indeed, sophisticated interest groups can construct contracts that nullify competition (almost) completely. The paper also highlights that the effectiveness of various policy tools designed to curb outside influence depends crucially on the presence or absence of competition. One such tool, the extension of the voting franchise, is shown to sometimes have the perverse effect of making it cheaper for interest groups to wield influence, but only in the presence of competition. Another tool, the secret ballot, proves a robust deterrent in the presence of competition, but is of much less help in curtailing influence when competition is absent. Hence, in developing anti-corruption policies, policy makers have to think carefully about the presence or absence of competition among interest groups seeking to wield influence and about the contracting environment. 


\section{References}

[1] August, Oliver (2000) 'Betting Alters the Odds in Close Taiwan Election,' The Times (London), March 15.

[2] Banks, Jeffrey S. (2000) 'Buying Supermajorities in Finite Legislatures,' The American Political Science Review 94: 677-681.

[3] Baron, David P. (2000) 'Legislative Organization with Informational Committees,' American Journal of Political Science 44: 485-505.

[4] Bernheim, B. Douglas and Michael D. Whinston (1986) 'Menu Auctions, Resource Allocation, and Economic Influence,' Quarterly Journal of Economics 101: 1-31.

[5] Buffett, Warren (2000) 'The Billionaire's Buyout Plan,' The New York Times, September 10 .

[6] Caro, Robert A. (1982) The Years of Lyndon Johnson: The Path to Power. New York: Alfred A. Knopf.

[7] Cox, Gary W. and J. Morgan Kousser (1981) 'Turnout and Rural Corruption: New York as a Test Case,' American Journal of Political Science 25: 646-663.

[8] Dal Bo, Ernesto (2007) 'Bribing Voters,' American Journal of Political Science 51: 789-803.

[9] Dekel, Eddie., Matthew O. Jackson and Asher. Wolinsky (2005) 'Vote buying,' Caltech Working Paper.

[10] Ford, Paul Leicester (1896) The True George Washington. Philadelphia: J.B. Lippincott Co. 
[11] Gilligan, Thomas W. and Keith Krehbiel (1987) 'Collective Decision-Making and Standing Committees: An Informational Rationale for Restrictive Amendment Procedures,' Journal of Law, Economics, and Organization 3:287-335.

[12] Gilligan, Thomas W. and Keith Krehbiel (1989) 'Asymmetric Information and Legislative Rules with a Heterogeneous Committee,' American Journal of Political Science 33:459-490.

[13] Groseclose, Timothy and Jason Snyder (1996) 'Buying Supermajorities,' American Political Science Review 90: 303-315.

[14] Grossman, Gene M. and Elhanan Helpman (1994) 'Protection for Sale,' American Economic Review 84: 833-850.

[15] Grossman, Gene M. and Elhanan Helpman (1999) 'Competing for Endorsements,' American Economic Review 89: 501-524.

[16] Grossman, Gene M. and Elhanan Helpman (1996) 'Electoral Competition and Special Interest Politics,' Review of Economic Studies 63: 265-286.

[17] Heckelman, Jac C. (1998) 'Bribing Voters Without Verification,' The Social Science Journal 35: 435-443.

[18] Morgan, John and Felix Várdy (2011) 'Negative Vote Buying and the Secret Ballot,' Journal of Law, Economics, and Organization (Forthcoming).

[19] Nitzan, Shmuel. (1994) 'Modeling Rent Seeking Contests,' European Journal of Political Economy 10: 41-60. 
[20] Newman, Terry (2003) 'Tasmania and the Secret Ballot,' Australian Journal of Politics and History 49: 93-101.

[21] Persson, Thorsten., Guido Tabellini and Francesco Trebbi (2003) 'Electoral Rules and Corruption,' Journal of the European Economic Association 1: 958-989.

[22] Quimpo, Nathan (2002) 'A Season of Vote Buying and Kidnappings,' http://www.ipd.ph/features/july_2003/barangay_sk_elections.html

[23] Seymour, Charles M.A. (1915) Electoral reform in England and Wales: The development and operation of the parliamentary franchise, 1832-1885. New Haven: Yale University Press.

[24] Shaffer, F. (2002) 'What is Vote Buying?' manuscript prepared for delivery at conference on 'Trading Political Rights: The Comparative Politics of Vote Buying,' Center for International Studies, MIT, Cambridge, August 26-27.

[25] Tullock, Gordon (1972) 'The Purchase of Politicians,' Western Economic Review 10: $354-55$.

[26] Tullock, Gordon (1980) 'Efficient Rent-seeking,' in James M. Buchanan, Gordon Tullock and Robert Tollison (eds) Toward a theory of the rent-seeking society. College Station: Texas A\&M Press.

[27] Webster, Hutton (1920) Historical Source Book. Boston: D.C. Heath and Co. 


\section{Notes}

${ }^{1}$ We use the term voting body as a generic description for a wide range of institutions where decisions are made by voting. For example, legislatures, committees, and voters in general elections all constitute voting bodies.

${ }^{2}$ See "Olympic 'vote buying' scandal” BBC News, December 12, 1998.

http://news.bbc.co.uk/1/hi/world/europe/233742.stm

${ }^{3}$ To ease exposition, we slightly modify the notation of GS. Readers desiring additional details or justification for the model may want to consult their paper.

${ }^{4} \mathrm{~A}$ similar assumption arises in the literature on legislative rules with respect to the commitment of the median floor legislator to a particular rule (see Gilligan and Krehbiel 1987, 1989). Baron (2000) makes the same assumption in studying transfers between the floor and the committee as a function of the bills reported out of the committee.

${ }^{5}$ The non-generic case where exactly a bare majority of voters prefer policy $b$ produces identical results in all cases save for when contracting is restricted to be contingent on outcomes only. In that case, group $A$ can succeed in achieving its preferred policy outcome by exploiting the (unrealistic) fact that all voters are pivotal even absent any contracts.

${ }^{6}$ The openness of the time interval at $\tau=1$ ensures that there is no "last moment," such that an interest group always has the opportunity to react to contract offers made by the opposition.

${ }^{7}$ Because the strategies of interest groups are functions, we cannot directly adopt Selten's 
trembling hand refinement for extensive form games.

${ }^{8}$ Instead of a grid that grows finer as $n$ increases, we could have used a replicator set-up. This does not change the results.

${ }^{9}$ Of course, this preference function is not strictly decreasing in the index. Changing the example to exactly fit this assumption is just a matter of adding tiny amounts of slope and making the preference function continuous at the jump points. This can all readily be done while affecting the costs by only an infinitesimal amount. We opted not to do this here, because it obscures the fundamental intuition of the example without adding any economic content. Detailed notes for a fully-fledge continuous example are available from the authors upon request.

${ }^{10}$ This practice is called "Telegraphing" in Cambodia, and "Lanzadera" (Spanish for "shuttle") in the Philippines. (Shaffer, 2002.)

${ }^{11}$ In a companion paper (Morgan and Várdy, 2011) we study negative vote buying when the payoffs from abstention lie halfway between the payoffs from voting for $a$ and the payoffs from voting for $b$. We show that the resultant least-cost contract is qualitatively similar to a $K\left(m^{*}\right)$ contract.

${ }^{12}$ This result does not, in an essential way, rely on a voter believing that he is pivotal with zero probability. If a voter ascribed a small but positive probability to being pivotal, group $A$ could pay him a transfer to switch his vote from $b$ to $a$. But the necessary transfer becomes unbounded as the probability of being pivotal goes to zero in the limit.

${ }^{13}$ Again, notice that there always exists an equilibrium in which all voters ignore the 
outcome-based contract and vote according to their intrinsic preferences.

${ }^{14}$ See "Olympic 'vote buying' scandal” BBC News, December 12, 1998.

http://news.bbc.co.uk/1/hi/world/europe/233742.stm

${ }^{15}$ See also Banks (2000).

${ }^{16}$ See also Persson, Tabellini, and Trebbi (2003) for an overview. 


\section{A Proofs of Propositions}

\section{Proof of Proposition 2}

Suppose, to the contrary, that neither interest group offers contracts. In that case, $A$ can profitably deviate by offering the monopoly contract and obtaining its preferred policy at a $\operatorname{cost} C_{\text {Monopoly }}<W_{A}$.

Next, suppose that $B$ moves before $A$. Define $V$ to be the set of voters that accept $B$ 's contract if $A$ stays out. Since $B$ is a monopolist with infinitesimal probability, payments made to voters in $V$ must be less than or equal to $W_{B}$. Suppose that $A$ responds as follows: It "negates" all of $B$ 's offers to voters in $V$ and, in addition, offers the monopoly contract. Negation consists of offering the same amount as $B$ in exchange for an $a$ vote. Adding the monopoly contract consists of offering voters with type $v^{-1}(0) \leq i \leq M$, an additional amount $-v_{i}$ in exchange for an $a$ vote. Since the cost of negation is, at most, $W_{B}$, while the cost of adding the monopoly contract is $C_{\text {Monopoly }}$, $A$ 's total expenditure on vote buying following a move by $B$ is at most $W_{B}+C_{\text {Monopoly }}<C_{A}\left(m^{*}\right)<W_{A}$. Therefore, this is a profitable response by $A$. As a result, $B$ can do no better than to wait for $A$ to move first. In fact, because with infinitesimal probability group $B$ is a monopolist which gets its way even if it does nothing, moving first leaves $B$ strictly worse off.

Finally, suppose that $B$ moves at the same time as $A$. When the coin flip determines that $B$ goes first, then, by the same argument as above, $B$ is strictly better off moving second. When the coin flip determines that $A$ goes first, $B$ is just as well off as when it offers contracts after $A$ has already moved. Therefore, $B$ is strictly better off moving second.

\section{Proof of Proposition 4:}

We will show that for any contract offered by $A$, there exists a subgame perfect equilib- 
rium where policy $b$ is adopted. To see this, suppose group $A$ offers some arbitrary contract, group $B$ does nothing, and voters vote according to their intrinsic preferences. Since $A$ 's contract is only contingent on outcomes, it is payoff relevant to voter $i$ only to the extent that $i$ is in a position to alter the outcome by his vote. Furthermore, since $b$ commands a supermajority of intrinsic support, then, under the putative equilibrium, each voter has zero probability of affecting the policy by changing his vote. At the same time, changing one's vote from $b$ to $a$ leads to a first order payoff effect in the amount $v_{i}$. Therefore, voters can do no better than to vote according to their intrinsic preferences. Furthermore, since $B$ obtains its preferred outcome at no cost, it can do no better than to do nothing. Note that this argument does not rely on any particular order of moves.

\section{Proof of Proposition 5:}

First note that $A$ cannot successfully buy a supermajority since, were $A$ to do so, no member of the supermajority coalition would be pivotal. In that case, voting according to intrinsic preferences is optimal and policy $b$ would be adopted. Hence, $A$ must be buying a simple majority.

To successfully deter $B$ with a simple majority, it must be the case that the cost to $B$ of recruiting a single member of $A$ 's coalition is at least $W_{B}$. Thus, all members of the $A$ coalition must obtain surplus of at least $W_{B}$ when $a$ is adopted

Next, notice that all voters in $A$ 's coalition who are promised a positive payment in the event that $a$ is adopted must earn the same surplus. (If not, then such a contract is not least cost, since $A$ could successfully offer a cheaper contract by lowering the payments to those receiving the higher surplus.). Thus, it must be the case that, if voter $i$ is in $A$ 's coalition and receives a positive transfer, this transfer must be $W_{B}-v_{i}$. Finally, notice that an (outcome 
based) $K(M)$ contract is a least-cost contract satisfying these properties.

To see that there exist equilibria in which policy $a$ is not adopted following the offer of the $K(M)$ contract by $A$, suppose that $B$ does nothing and that all voters simply vote according to their intrinsic preferences. Then, because $v_{M-1}<0$, policy $b$ is adopted. Finally, since no voter is pivotal, voters can do no better than to vote according to their intrinsic preferences.

\section{Proof of Proposition 6:}

For a contract to be successful, it must deter $B$ from successfully recruiting a majority of any size. To deter $B$ from recruiting a bare majority it must be the case that, for any bare majority recruited by $B$, the outside options of those recruited - which consist of the joint event of voting for $a$ and $a$ winning - must sum up to at least $W_{B}$.

We claim that the cheapest way of doing this entails a $K\left(m^{*}\right)$ contract. Suppose not. Then there exists a contract such that $B$ is deterred from recruiting a bare majority which costs less than $K\left(m^{*}\right)$. Suppose under this alternative contract, $B$ has to recruit $m^{\prime}-M$ voters to obtain a bare majority. Clearly, $B$ will choose the voters whose outside option under the contingency that they defect from $B$ 's coalition is the smallest. Therefore, it must be the case that the surplus of these voters under the contingency the joint of voting for $a$ and policy $a$ being chosen sums to $W_{B}$. Moreover, this must be true of all coalitions of size $m^{\prime}-M$.

Next, notice that all voters recruited into $A$ 's coalition who are promised a positive payment in the event that they vote for $a$ and $a$ is chosen must earn the same surplus. Let this surplus amount be $S$. (If not, then such a contract is not least cost since $A$ could successfully offer a cheaper contract by lowering the payments to those receiving the higher 
surplus.). Thus, it must be the case that, if voter $i$ is in $A$ 's coalition and receives a transfer, this transfer must be $S-v_{i}$ under the contingency that $i$ votes for $a$ and policy $a$ is adopted. But now recall that a $K\left(m^{*}\right)$ contract is in fact the least-cost contract satisfying this property while still deterring $B$. Contradiction.

Hence, if $A$ offers a $K\left(m^{*}\right)$ contract, it will successfully deter $B$ from recruiting a bare majority and furthermore, it is the cheapest possible way to do it.

Next, to deter $B$ from recruiting a supermajority, it must be the case that the outside options, which consist of the joint event of voting for $a$ and $a$ losing, must sum to at least $W_{B}$. The $K\left(m^{*}\right)$ contract satisfies this condition. Hence, a $K\left(m^{*}\right)$ contract is a least-cost successful contract.

\section{Proof of Proposition 7:}

Suppose there exists an equilibrium in which $B$ moves first and gets its preferred policy $b$ adopted in the election. Suppose that $A$ counters by offering a $K\left(m^{*}\right)$ contract. Because policy $b$ is adopted, at least $m^{*}-M$ voters who were offered the $K\left(m^{*}\right)$ must have turned it down in favor of $B$ 's contract. However, by construction of $K\left(m^{*}\right)$, to achieve this must have cost $B$ at least $W_{B}$. Hence, offering this contract was not profitable for $B$. Contradiction.

\section{Proof of Proposition 8:}

First, we show that the contract in the proposition is least-cost. Note that, in equilibrium, the cost of the contract is

$$
\sum_{i=1}^{M+1} \max \left(-v_{i}, 0\right)
$$

and recall that, in the absence of competition, the minimum cost of obtaining \# $a=m$ votes is

$$
C_{A}(m)=\sum_{i=1}^{m} \max \left(-v_{i}, 0\right)
$$


Therefore, the only contracts with potentially lower costs have $\# a=M$. What do successful contracts of that sort look like? To deter $B$ from re-bribing one voter and obtaining his preferred policy, all voters voting for $A$ must receive a surplus of at least $W_{B}$ in the event that $A$ is approved with exactly $M$ votes. Hence, these contracts are strictly more costly than the contract in the proposition.

It remains to show that the contract in the proposition is a successful contract. We claim that if $A$ offers this contract, $B$ can do no better than doing nothing, and voters $i \leq M+1$ can do no better than voting for $a$.

First, suppose $B$ does nothing and consider a deviation by any voter $i$ currently voting for $a$. By deviating from $a$ to $b$, the voter earns

$$
\Delta U_{i}=-v_{i}-t_{i}
$$

For $i<v^{-1}(K(M+1)), v_{i}>0$ and $t_{i}=0$. Hence this is strictly unprofitable. For $v^{-1}(K(M+1)) \leq i \leq M+1, t_{i} \geq-v_{i}$ and, therefore, $\Delta U_{i} \leq 0$. Hence this is also unprofitable.

Next, we show that $B$ has no profitable deviation. Clearly, if $B$ offers a contract that does not alter the policy, it does not benefit. Suppose $B$ alters the policy by recruiting $k \geq 2$ voters from $A$ 's coalition. To induce these voters to switch, each must be paid the value of his outside option conditional on policy $b$ being adopted or policy $a$ being adopted with a bare majority (since these are the two possible contingencies associated with deviating from $b$ to $a$ when $k \geq 2)$. That is, for all $k$, each voter must be paid an amount at least $K(M+1)$ and, by construction

$$
k K(M+1) \geq W_{B}
$$

for $k \geq 2$. Therefore, $B$ has no profitable deviation. This completes the proof. 


\section{Proof of Proposition 10:}

First note that, given $A$ 's offer, $B$ 's unique best response is to choose the null contract. To see this, note that $B$ would have to recruit up to the median voter, $M$, if he wanted to implement policy $b$. To do so, he has to offer at least an amount $t_{B}=\frac{W_{B}}{M}+\varepsilon, \varepsilon>0$. This offer will be accepted by all constituents with indices $i \geq M$. Thus, any contract in which $B$ gets its preferred policy costs at least

$$
C_{B}=W_{B}+M \varepsilon
$$

and since this strictly exceeds the value to $B$ of its preferred policy, $B$ is strictly better off offering the null contract.

Thus, we have shown that $A$ 's offer constitutes a successful contract. It remains to show that it is also least-cost. Suppose that $A$ offers a transfer $t_{A}^{\prime}<t_{A}$, then by offering $t_{B}=t_{A}^{\prime}-v_{M}+\varepsilon$, group $B$ will attract all voters with indices $i \geq M$. For $\varepsilon$ sufficiently small, this contract will cost $B$ less than $W_{B}$ and, hence, $A$ 's contract is not successful.

Therefore, the contract described in the proposition is indeed the least-cost successful contract.

\section{Proof of Proposition 11:}

For a supermajority of voters to receive payments from $A$, it must be the case that voter $M+1$ is in $A$ 's coalition. This amounts to the condition that

$$
v_{M+1}+t_{A} \geq 0
$$

Substituting for $t_{A}$, we obtain

$$
v_{M+1}-v_{M}+\frac{W_{B}}{M} \geq 0
$$


Noting that $v_{M+1}<v_{M}<0$, it is convenient to rewrite this inequality as

$$
v_{M}-v_{M+1} \leq \frac{W_{B}}{M}
$$

which holds by Assumption 1.

\section{Proof of Proposition 12}

If $A$ moves first, then he will have to offer a transfer $t_{A, 1}=-v(M)+\frac{W_{B}}{M}$, where the first term corresponds to making the median voter indifferent, while the second term is the minimal transfer to block $B$ from making a counter offer. The cost of this contract to $A$, which by assumption is smaller than $W_{A}$, is at least $M t_{A, 1}$. If $B$ were to move first, the

transfer he would be willing to offer, $t_{B, 1}$, is at most $\frac{W_{B}}{M+1}$. A successful counteroffer by $A$ entails a transfer $t_{A, 2}=-v(M)+t_{B, 1}$. The cost of this counteroffer is $M t_{A, 2}$, which is strictly less than $M t_{A, 1}$. Hence, there is no subgame perfect equilibrium in which $B$ moves first.

\section{B Rationing}

One may worry that the supermajority result for non-discriminatory vote buying solely arises from the fact that $A$ cannot ration the set of voters who take up its offer. Here, we show that this is not the case. Let us amend the model as follows. Suppose that each of the groups are restricted to offering each constituent either the null contract or a $t$ contract where $t$ is a fixed transfer that does not depend on the identity of the constituent. Thus, by offering null contracts to certain voters, a group can ration its transfers.

To obtain the supermajority result for the case of rationing, preferences need to approximate the continuous relative preference model of Groseclose and Snyder. Hence, we extend Assumption 1 to all voters. Specifically, we assume that 
Assumption 2. For all $i, v_{i}-v_{i+1} \leq \frac{W_{B}}{M}$.

Proposition 13 Let vote buying be non-discriminatory. Then, under a least-cost successful contract with rationing, A always buys a supermajority of voters.

Proof. Suppose $A$ successfully recruits a simple majority. That implies that all voters $i=1,2, \ldots, M$ must enjoy a payoff of at least $W_{B}$. The cost to $A$ of this scheme is

$$
C_{A}^{M}=\left(W_{B}-v_{M}\right)\left(M-v^{-1}\left(W_{B}\right)+1\right)
$$

Now suppose $A$ successfully recruits a supermajority of $M+1$. This implies that all voters $i=1,2, \ldots, M+1$ must enjoy a payoff of at least $\frac{W_{B}}{2}$. The cost to $A$ of this scheme is

$$
C_{A}^{M+1}=\left(\frac{W_{B}}{2}-v_{M}\right)\left(M+1-v^{-1}\left(\frac{W_{B}}{2}\right)+1\right)
$$

From Assumption 2 it follows that

$$
v^{-1}\left(\frac{W_{B}}{2}\right)-v^{-1}\left(W_{B}\right) \geq 1
$$

Hence, $C_{A}^{M+1}<C_{A}^{M}$. 


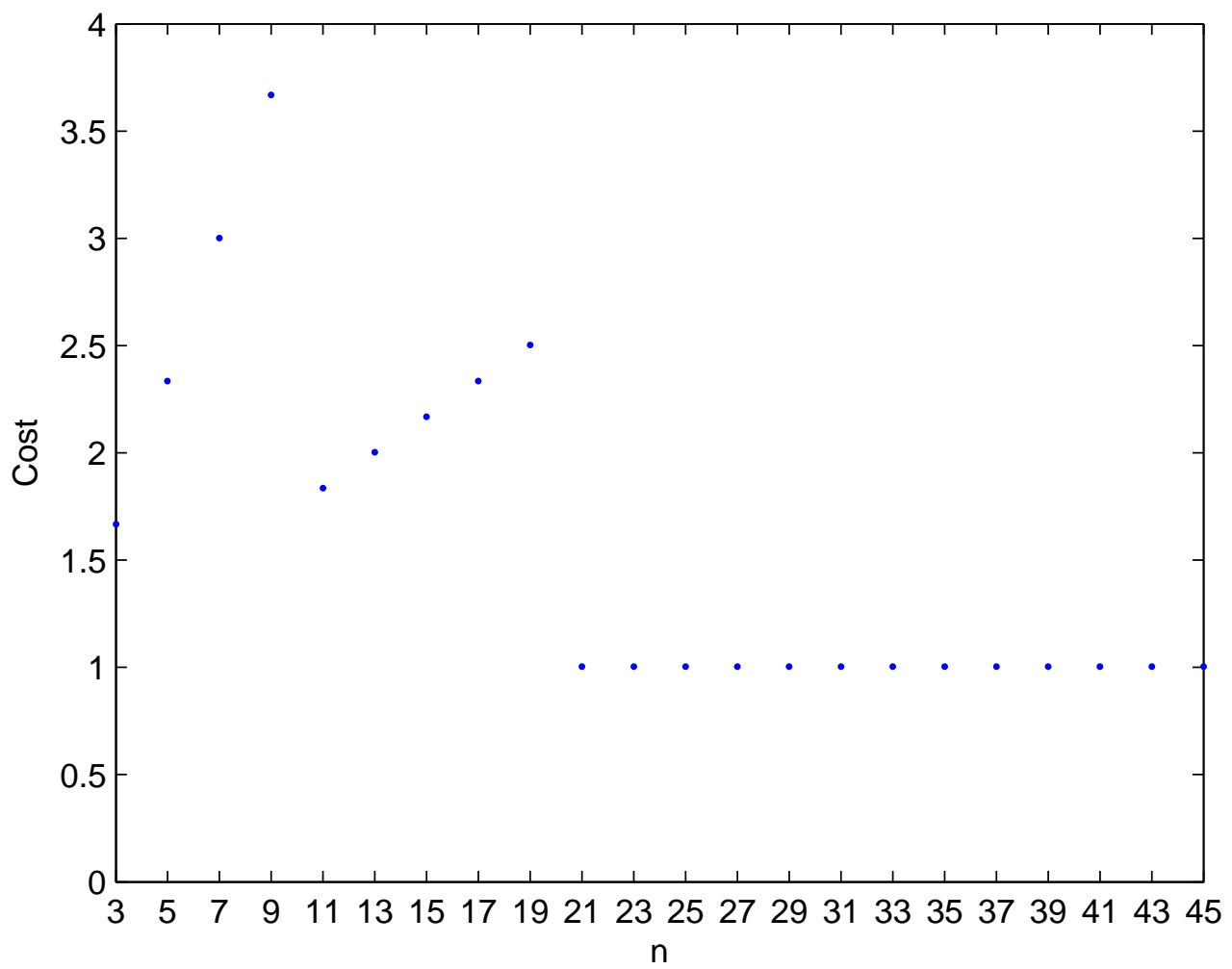




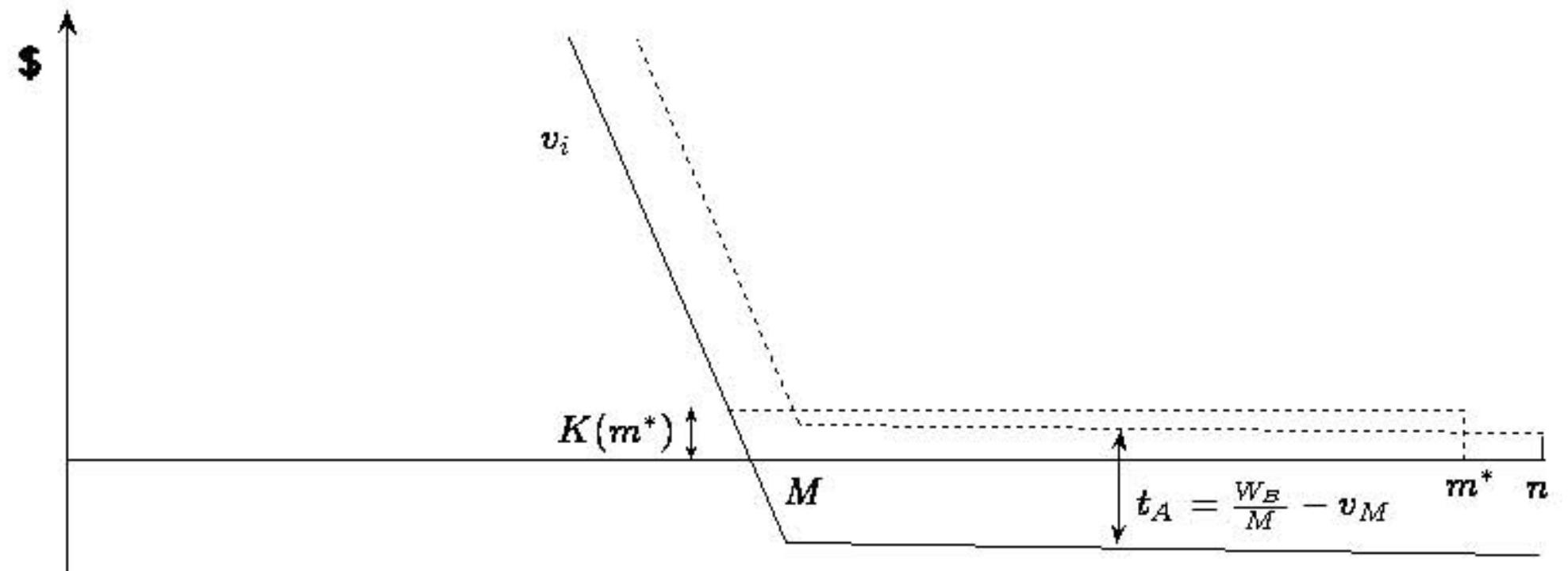




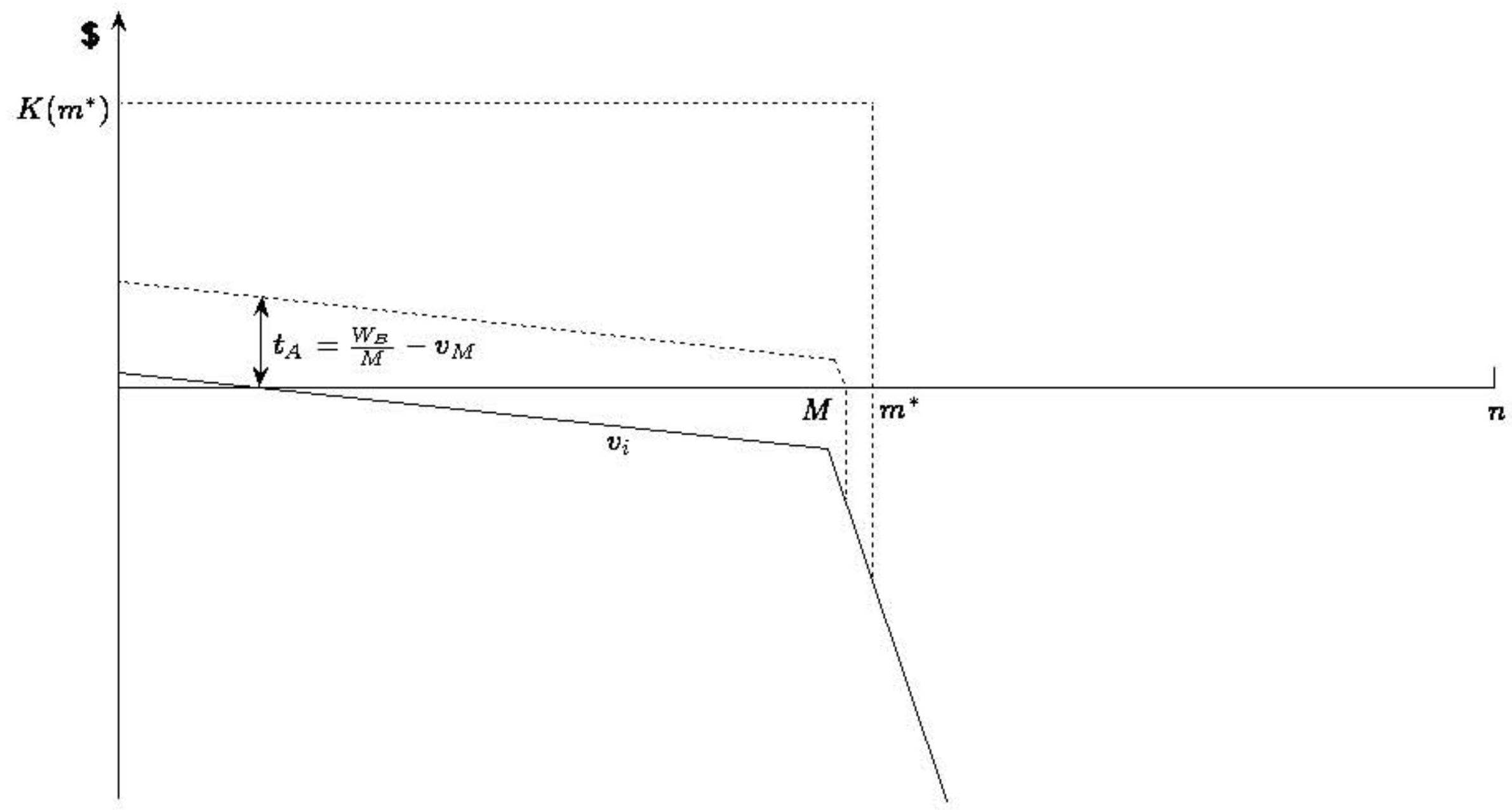

